\title{
Paradox of Illustration Facilitating/resisting Translation in Comic Strips
}

\begin{abstract}
This paper is an attempt to comprehend the problematic involved in translating comic strips. Since the use of illustration in comics works as a vehicle for communicating cultural values, the scope of investigating comic strips such as Tintin's Adventures in translation from English to Bengali becomes a valid project and this paper attempts to do the same. The very fact that translation of a comic strip entails no translation of the anchorage text but the relay text only presents itself as an interesting problematic. The illustration paradoxically facilitates and resists translation in comic strips.
\end{abstract}

Archita Gupta

The process of translation presents itself as an interesting paradigm when the praxis is translation of comic strips. The concept of language-codification and pictorial codification in comic strips-in the form of illustration and familiar comic strip iconography such as, stars for pain, speech bubbles and thought balloons, sawing logs for snoring etc-have evolved a new pictorial language that remains valid and meaningful across cultures and languages in the form of modern and popular archetypal constructs. Hence, translating a comic strip would require translation of the language part only, leaving the rest consisting of illustration, speech balloon and thought bubble etc as it is. This then leads to a part of the hypothesis that this paper attempts to arrive at, that is, illustration facilitates translation in comic strips. Moreover illustrations in a comic strip help in grounding the text in a specific socio-cultural milieu. This could be read as a strategy of resistance that ensures safeguarding its original cultural identity since 
trans-culturation is denied. The result is a paradox-a binary of help and hindrance. In this context, a popular comic strip such as Tintin's Adventures translated from English to Bengali and published and marketed by Ananda Publishers, Kolkata presents an interesting case study.

Since this paper is an attempt to comprehend the dynamics of the problem involved in translating comic strips via language and illustration, it becomes pertinent to understand the multiple levels at which a comic strip operates to generate meaning. The subtext operates in comic medium more emphatically through its action-oriented progression of plots. Comic medium is more akin to film medium than it is to the photographic image. Using Barthes' analogies in "The Rhetoric of Image", one can see that while photographic reality involves an awareness of 'having been there' or 'the stupefying evidence of this is how it was, giving us, by a precious miracle of reality from which we are sheltered' ${ }^{1}$, the dramatic element or the progress in action is constituted by the 'de-stilling' of the images through the continuity of images in the comic medium. Just as the photographic image is related to a 'pure spectatorial consciousness', the film medium depends on "a more projective, more 'magical' fictional consciousness" 2 .

The film medium consequently involves an awareness of 'being there' rather than 'having been there'. The photograph can at best represent a 'flat anthropological fact'. The film on the other hand, with its present continuous narratives can establish links and therefore construct a story. Hence, there is a similarity between comic strip and film medium.

It is to be remembered here that considering the authority that is invested in the written word, it is very difficult to find a text that is exclusively made of images. There is almost invariably a minimal written caption. Barthes delineates two functions from the linguistic message that accompanies any image, namely, anchorage and relay. While the 'anchorage text', i.e. the illustration/image, is meant to 
direct the reader through the signified of the image causing him to avoid some and receive others, by means of an often subtle dispatching, it remote controls him towards a meaning chosen in advance. ${ }^{3}$

The anchorage text, in other words, becomes an occasion to display its overt ideology, in consonance with dominant social structure. The 'relay text', i.e. the linguistic message that is found in cartoon and comic strips is not more than 'a scratch of dialogue' and it is complimentary to the image.

...the words, in the same way as the images, are fragments of a more general syntagm and the unity of the message is realised at a higher level than that of the story, the anecdote, the diegesis. ${ }^{4}$

The idea is to use dialogues for advancing the action and to add only those meanings that are not to be found in the image itself. In comic strips, the relay function of linguistic text operates along with its action-oriented medium. The awareness of 'being there' involves the reader at once.

In 1967, UNESCO endorsed the use of comics as a vehicle for communicating cultural values. As a consequence, the scope of investigating comic strips such as Tintin's Adventures in translation from English to Bengali becomes a valid project and this paper attempts to do the same. The discourse originates from the concept of translation as a process that refers to and involves a transformation from a source language to a target language along with the cultural nuances of the former.

When translation of a comic strip is undertaken, it is inevitably the translation of the relay text that is attempted while the anchorage text is left untranslated. Tintin comics in translation from English to Bengali conforms to this paradigm and hence, only the relay text in 
speech balloons etc is translated into Bengali. The looks of the characters, their behavioral pattern and mannerisms, the setting, the locale as depicted in the anchorage text remains untranslated. Rather it could be said that the task of the translator in translating the source culture of which the language/relay text is a part, for assuring proper translation, is made easy as the anchorage text visually communicates the cultural nuances involved.

The anchorage text of a comic strip, by remaining untranslated or by not requiring translation, communicates to a target reader the essential nuances of the source culture. Thus translation is facilitated by illustration or the anchorage text in a comic strip as it negotiates the degree of difficulty/problematic of translation to a considerable extent. This is because the anchorage text generates cultural connotations through illustrations and images that remain unchanged in translation and also works through modern and popular comic strip archetypal iconography such as stars for pain, speech bubbles and thought balloons, sawing logs for snoring etc that are understood across cultures. Certain cultural connotations that are unique and typical to a source culture and therefore language, and have no linguistic equivalence in the target language render themselves untranslatable. The only way out in the translation of a conventional text-sans-illustration is footnoting. A comic strip in translation can negotiate this translational problematic to a considerable extent on account of the anchorage text of illustration no doubt, but this is only a part of the paradigm. Two panels from Tintin's Adventures, 'The Crab with the Golden Claws' and its Bengali version 'Kankra Rahasya' would emphasize this hypothesis. In the second and third panel of the third row, the relay text is translated not literally but by maintaining the same connotation, whereas the anchorage text consisting of illustration and images remains intact with stars around Tintin's figure in both English and Bengali versions communicating pain via the popular archetypal comic strips iconography of stars symbolizing pain. 

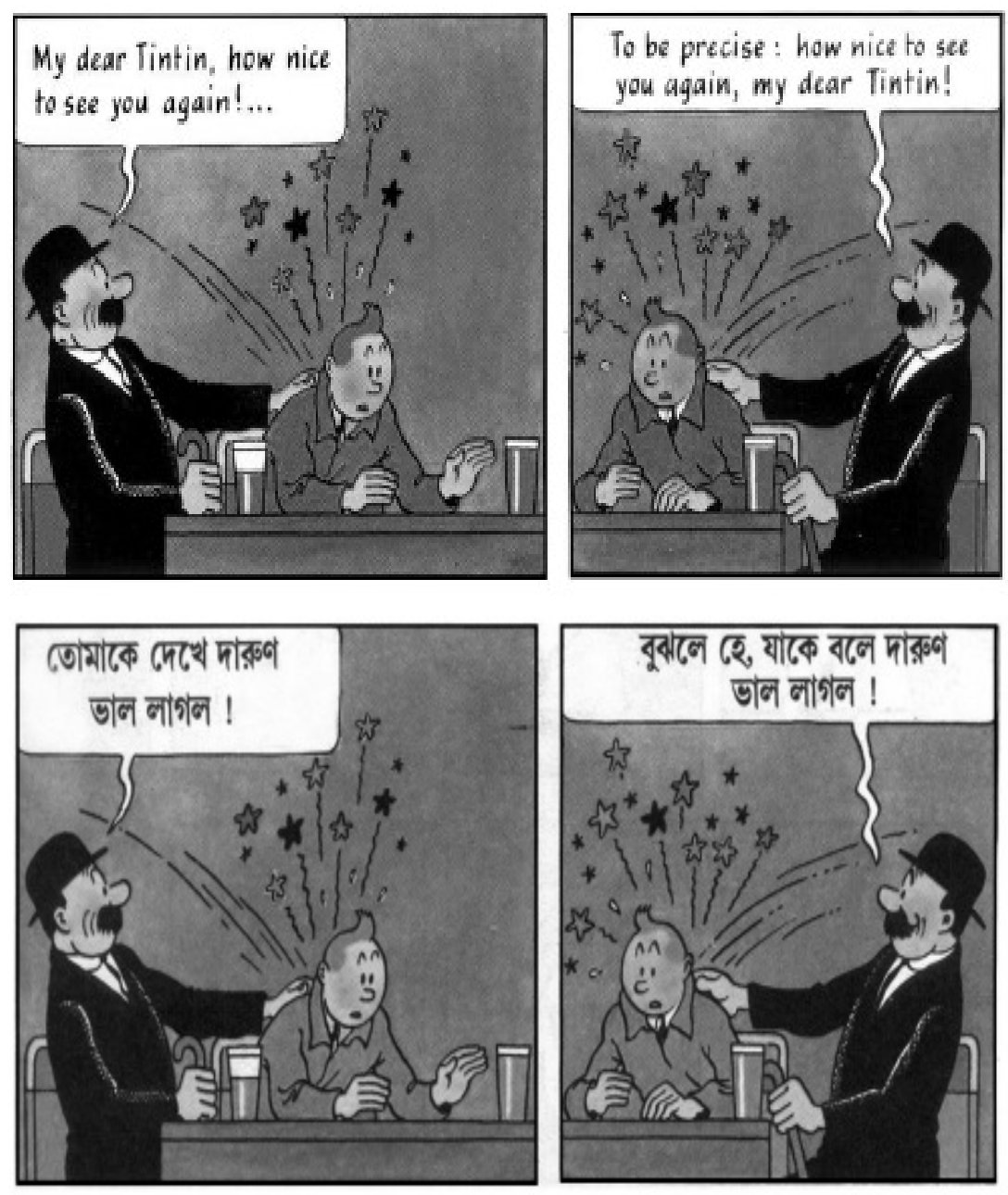

The very fact that translation of a comic strip entails no translation of the anchorage text but the relay text only, presents itself as an interesting problematic. In any translation, the most significant responsibility of the translator is to translate and convey the cultural traces that are unique and representative of the source culture and language. Hence, the efficiency of translation depends on accomplishing 
this task properly. The translator automatically runs the risk of loosing many or a few of these traces in the translation of a text-sans-illustration since the target language and culture, shaped by different geographical, climatic and other parameters, may not have equivalent morphological and semantic devices to convey those traces in the target language. This leads to approximation and ambiguity. The anchorage text consisting of images and illustrations in the case of a comic strip in translation would firmly and definitively ground itself in the source culture and leave no scope for such cultural ambiguity and linguistic approximation. The anchorage text would thus resist translation and preserve the cultural purity of the source culture by rendering itself untranslatable. The Tintin comic strip in translation from English to Bengali also shows the same tendency of resisting a loss of cultural connotations by retaining the anchorage text intact and unchanged, though the name of Tintin's pet dog gets translated from Snowy to Kuttush, and Thomson and Thompson, the detective duo, become Johnson and Ronson in the relay text.

In the second panel of the first row in page 35 of the translated Bengali version of the same adventure, the anchorage text consisting of illustration communicates the cultural traces and nuances of the deserts of Arabia through a depiction of the topography consisting of sand dunes, camels and turbaned figures. In this panel, though the relay text is translated from English to Bengali, the anchorage text anchors the cultural connotations firmly in the root culture and resists any loss or ambiguity which is otherwise inevitable in the translation of the relay text only.

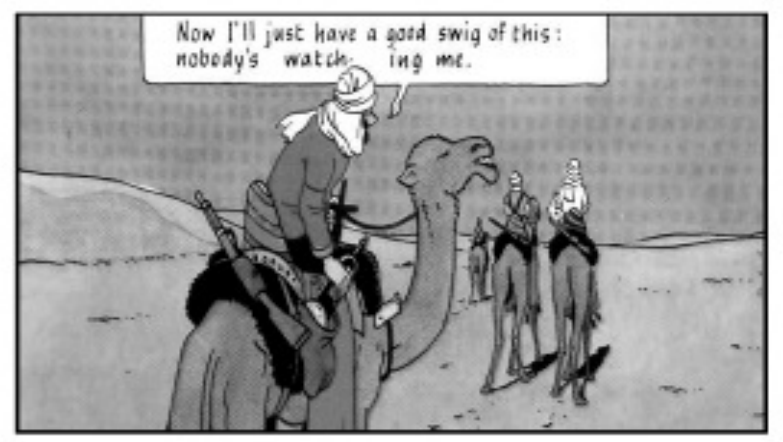




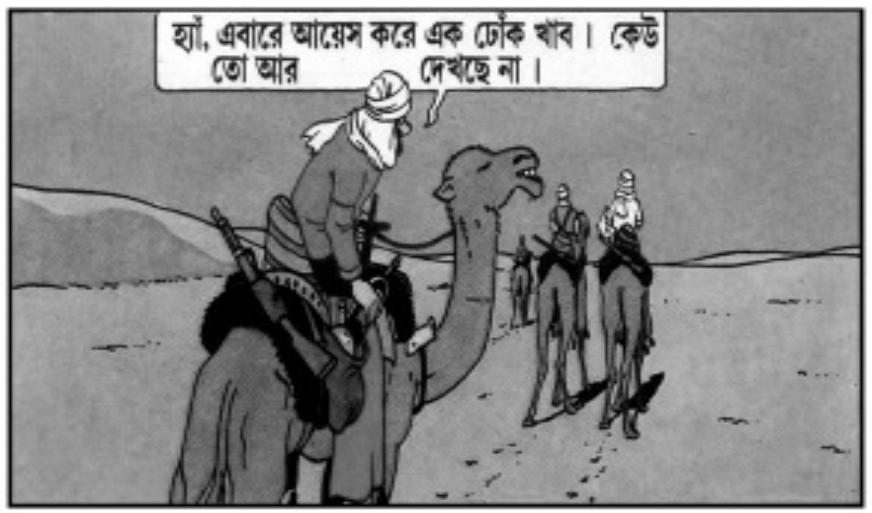

However there are a few exceptional cases and instances where, due to certain extra-linguistic and purely cultural and political reasons, the relay text accompanying the anchorage text in a comic strip is omitted, modified or silenced.

This is the other side of the paradigm where translation involves a deliberate loss/omission on the part of the translator. This happens due to a difference in the perspective, ideology and political indoctrination between the source culture and language and target culture and language, between the author and the translator.

Tintin comics in English version often make use of racist terms such as 'niger' etc for an African or an Arab. These terms are racially prejudiced and represent a white Eurocentric racist viewpoint. But, in Bengali translation such terms are not only avoided but the relay text, accompanying the anchorage text, is also silenced. This could be viewed as a clash of ideologies between the oriental and the occidental. Bengali being an oriental language and the language of the translator, she would sympathise with and relate to an Arab or an African rather than to a white European or white American. Therefore, it would only be politically correct to deliberately silence the racist relay text accompanying the anchorage text in the Bengali translation. Moreover, this also reverses the author-translator hierarchy by bestowing in the translator the authority to change/modify the original text while translating. 
In the first panel of the third row in the English version of 'The Crab with Golden Claws', Captain Haddock uses the word 'bunch of savages' in the relay text to denote the turbaned and robed oriental others of the original text. This is a purely racist abuse used from the white Eurocentric point of view. The same panel in page 41 of translated Bengali version totally silences this racist abuse and communicates a far safer connotation of just losing Tintin. In fact, in the original version, the relay text communicated two messages - one of racial connotation and the other of losing Tintin, and captain Haddock being bewildered. The translated Bengali version translates only the second message of the relay text and annihilates the first message. It goes against the ethos of Bengali culture which is oriental and non-Eurocentric. Moreover, this racist message would have gone against the sentiments of the Bengali reader.
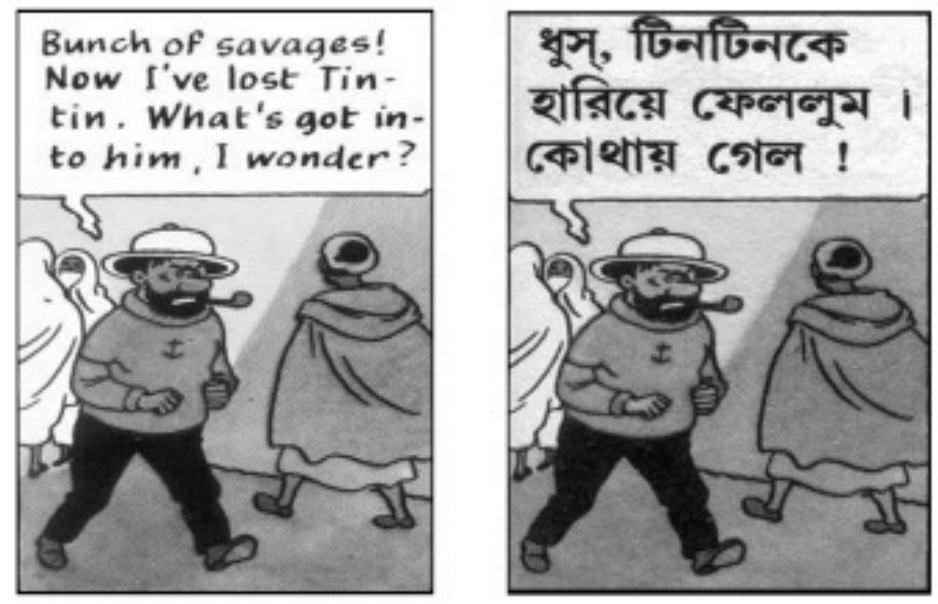

Thus, an analysis of comic strips in translation such as Tintin comics from English to Bengali reveals that under its apparent simplicity it conceals varied cultural, social and political forces at play. The process of translation of comic strips involves further complications since the anchorage text comprising of images and illustrations paradoxically facilitates and resists translation at the same time. This paper was an 
attempt at reading into this essential binary of help and hindrance that translation of a comic strip generates.

\section{Notes}

1 Barthes, Roland (1993) “The Rhetoric of Image", in Ann Gray and Jim McGerigan (eds) Studying Culture: An Introductory Reader, London: Edward Arnold.

2 ibid

3 ibid

4 ibid

\section{References}

Taylor, E.B. (1871) Primitive Culture, London: Papyrus.

Williams, Raymond (1967) 'Culture and Civilisation', The Encyclopedia of Philosophy, New York: Macmillan, 273.

Herge (1974) The Adventures of Tintin: The Crab with the Golden Claws, New York: Little, Brown and Company.

Herge (2006) 'Kankra Rahasya', Kolkata: Ananda Publishers Pvt.

Ltd. 